\title{
Erratum to: Power and phase properties of oscillatory neural responses in the presence of background activity
}

\author{
Nai Ding • Jonathan Z. Simon
}

Published online: 17 February 2013

(C) Springer Science+Business Media New York 2013

\section{Erratum to: J Comput Neurosci}

DOI 10.1007/s10827-012-0424-6

The original version of this article contained an inaccurate grant number. The Acknowledgements section, with the correct grant number, is reproduced in full below.

Acknowledgements We are grateful to Mary F. Howard and David Poeppel for insightful comments and discussion. This research was supported by the National Institute of Deafness and Other Communication Disorders Grant R01-DC-008342.

The online version of the original article can be found at http://dx.doi.org/ 10.1007/s10827-012-0424-6.

N. Ding $\cdot$ J. Z. Simon

Department of Electrical and Computer Engineering,

University of Maryland,

College Park, MD 20742, USA

N. Ding

e-mail: gahding@umd.edu

J. Z. Simon $(\bowtie)$

Department of Biology, University of Maryland,

College Park, MD 20742, USA

e-mail: jzsimon@umd.edu 